\section{A Short communication on Pichia pastoris vs. E. coli: Efficient expression system}

\author{
Viswanath Vittaladevaram* \\ CURAM, National University of Ireland, Galway, Ireland
}

One of the major challenges for vaccine producing companies is having favourable conditions for efficient expression system for living organisms in order to produce biologicals. Several companies across the globe looking for several alternative sources for better yield through efficient expression based system.

E. coli is predominantly used bacterial species for production of recombinant proteins but since from past few years, Pichia pastoris is considered as ideal choice and it is considered as superior to $E$. coli as it overcomes specific limitations that are observed while using E.coli for recombinant protein production. One such limitation with reference to usage of E. coli is it's lack of ability to carry out the process of glycosylation during posttranslational modifications [1]. The process of glycosylation is critical for delivering therapeutic proteins and further it is tolerated by humans without exhibiting antigenic reactions. To overcome this, organisms such as Pichia pastoris is currently used in industries for recombinant protein production on large scale basis.

Pichia pastoris use methanol as energy source and it can be grown in cell suspension system containing methanol solution that is easy and cheaper to build and maintain. The process of culturing using Pichia pastoris is easier and it is more suitable for culturing and growth by using bioreactors [2]. The features are better equipped and it is found to be cost-effective and efficient expression system.

The reason why Pichia pastoris is superior to E. coli is its ability to conduct process of glycosylation which facilitates further to yield recombinant proteins in high quantity with less expenditure. Thus Pichia pastoris is found to be effective alternative source both in mammals and insect cell systems for production of recombinant proteins on large scale and further it enhance to carry out structural studies [3].

There are several advantages with the use of Pichia pastoris

\author{
More Information \\ *Address for Correspondence: \\ Viswanath Vittaladevaram, CURAM, National \\ University of Ireland, Galway, Ireland, \\ Email: viswa.vittal@gmail.com \\ Submitted: September 16, 2021 \\ Approved: September 28, 2021 \\ Published: September 29, 2021 \\ How to cite this article: Vittaladevaram $V$ \\ A Short communication on Pichia pastoris vs. \\ E. coli: Efficient expression system. Ann Proteom \\ Bioinform. 2021; 5: 049-050. \\ DOI: 10.29328/journal.apb.1001016 \\ Copyright: @ 2021 Vittaladevaram V. This \\ is an open access article distributed under \\ the Creative Commons Attribution License, \\ which permits unrestricted use, distribution, \\ and reproduction in any medium, provided the \\ original work is properly cited. \\ D) Check for updates \\ (2) open Access
}

as effective expression system over E. coli which is aimed at production of heterologous proteins. Classic advantages of Pichia pastoris include [4].

Ability to make complex proteins that is performed using subcellular machinery that is eukaryotic in nature.

These are essential to carry out post translational modifications which includes carrying out proteolytic mechanism, folding, formation of disulphide bond and process of glycosylation.

Several industries across the globe showed interest in using Pichia pastoris over E. coli for heterologous production of recombinant proteins since it is found to be cost effective, simple and fast in delivering high protein expression levels and also obtain maximal success rate in terms of recombinant protein expression. It is very easier to perform manipulation as similar to E. coli and it is inexpensive and provides high efficiency rate in terms of protein expression [5]. Pichia pastoris expression system is inexpensive over $E$. coli and it exhibits similarity with $\mathrm{CHO}$ cell lines of eukaryotic expression systems.

Pichia pastoris is a yeast methylotroph has benefit to carry out genetic and molecular manipulations and it enhance protein secretion into medium. Few examples of companies currently using Pichia pastoris as efficient expression system include Bio Grammatics, Life Technologies from USA and Biocon and Indian Immunological limited from India [6]. Importance of Pichia pastoris is mainly associated with 
development of vaccines against Hepatitis-Diabetes and Influenza and it also showed potential in order to develop different types of sub-unit vaccines in adequate proportions in industries.

\section{References}

1. Das S, Ramakrishnan K, Behera SK, Ganesapandian M, Xavier AS, et al. Hepatitis B Vaccine and Immunoglobulin: Key Concepts. J Clin Translational Hepatol. 2019; 7: 165-171.

PubMed: https://pubmed.ncbi.nlm.nih.gov/31293917/

2. Eck A, Schmidt M, Hamer S, Ruff AJ, Förster J, et al. Improved microscale cultivation of Pichia pastoris for clonal screening. Fungal Biol Biotechnol. 2018; 5: 8.

3. Kaushik N, Rohila D, Arora U, Raut R, Lamminmaki U, et al. Casamino acids facilitate the secretion of recombinant dengue virus serotype-3 envelope domain III in Pichia pastoris. BMC Biotechnol. 2016; 16: 12.

4. Legastelois I, Buffin S, Peubez I, Mignon C, Sodoyer R, et al. Nonconventional expression systems for the production of vaccine proteins and immunotherapeutic molecules. Hum Vaccin Immunother. 2017; 13: 947-961.

PubMed: https://pubmed.ncbi.nlm.nih.gov/27905833/

5. Rajamanickam V, Metzger K, Schmid C, Spadiut O. A novel bidirectional promoter system allows tunable recombinant protein production in Pichia pastoris. Microbial Cell Factories. 2017; 16: 152.

6. Vieira Gomes AM, Souza Carmo T, Silva Carvalho L, Mendonça Bahia F, et al. Comparison of Yeasts as Hosts for Recombinant Protein Production. Microorganisms. 2018; 6: 38.

PubMed: https://pubmed.ncbi.nlm.nih.gov/29710826/ 